\title{
Wstęp
}

\section{Emigracja i migracja}

Anna Nasiłowska

TEKSTY DRUGIE 2016, NR3, $5.7-10$

DOl: $10.18318 /$ td. 2016.3 .1

$\mathbf{L}$

iteratura emigracyjna? Nie, migracyjna. Fala współczesnych

wyjazdów z Polski po 2004 roku nie wzięła się z politycznego przymusu, także powody ekonomiczne migracji nie zawsze rysują się jednoznacznie. Bardzo często decyduje ciekawość, potrzeba przygody, wyjazd to także próba osiągnięcia szybkiego uniezależnienia się młodych ludzi od rodziny. Poczucie, że zawsze można wrócić, działa uspokajająco, choć w praktyce powroty napotykają na wiele przeszkód. Wyjazd to odważny wybór.

Nawet w XIX wieku sytuacja nie zawsze była jednoznaczna. Czy Mickiewicz musiał wyjechać? Raczej tak, opuścił Rosję w pośpiechu, tuż przed zaostrzeniem kursu politycznego, chwila zwłoki mogłaby spowodować odebranie mu paszportu byłby skazany na zamknięcie w Cesarstwie. Ale już ze Słowackim sprawa nie jest tak oczywista, czy musiał. Chciał. Pobyt na Zachodzie dawał mu dobre impulsy, zapewniał też poczucie absolutnej niezależności od cenzury i warunków politycznych. Podobnie Chopin - wyjechał, aby móc się spełniać artystycznie. W Królestwie Polskim byłby tylko artystą prowincjonalnym. A Słowacki nie ujrzałby żadnego dramatu Shakespearéa na scenie. Zobaczył w Londynie. Dzień, w którym oglądał legendarnego aktora Edmunda Keana w Ryszardzie III, uznał za niezwykle szczęśliwy. Takie motywacje wydają się bliskie współczesnym.

\section{Anna}

Nasiłowska - prof dr hab., pracownik IBL PAN, członkini Zespołu Literatura i Gender IBL PAN. Zastępca redaktora naczelnego "Tekstów Drugich". Ostatnı opublikowała biografię Marii Pawlikowskiej- Jasnorzewskiej (2010), wybór pism Stefanii Zahorskiej (2010), reportaz historyczny Woiny agent Umeda idruga japonia (2013), tom poezji Zywioty (2014) oraz Dyskont stów (2016). Wspótredaktorka Encyklopedii gender (2014). Kontakt: anna. nas(awp.p 
Migrację od emigracji dzieli jedna głoska - „e", ale przedrostek nie jest wykładnikiem wirtualności jak w wielu słowach zaopatrzonych w "e", choćby e-book czy e-zakupy. To emigracja ma twardy, określony sens, migracja to status płynny i zmienny. W XX wieku najbardziej jednoznaczna była sytuacja polskich uchodźców, którzy uciekli we wrześniu 1939 roku. Rzeczywiście musieli, wielu z nich groziła śmierć. Emigracyjne elity polityczne spełniły bardzo ważną rolę, a pisarze - może poza takimi ekscentrykami jak Gombrowicz - świadomie zaprzęgli się w kierat publicystyki i sami podsycali namiętności, jakie wyzwalała w nich najpierw wojenna sytuacja. Potem podjęli polityczne obowiązki wynikające z niezgody na rozstrzygnięcia, jakie zapadły wobec Polski pod koniec II wojny.

Choć emigrację i migrację różni tylko obecność lub brak jednej głoski, literackie dominanty ideowe tych zjawisk różnią się zasadniczo. Literatura emigracyjna XIX wieku była wizjonersko-mistyczna, a dwudziestowieczna - polityczna. Zajmowała się tematami, które postrzegała jako swój obowiązek wobec kraju, zgłaszała żądania o charakterze rewindykacji i wytwarzała silne więzi z przeszłością. Trwała w gotowości do działania i organizowała się wewnętrznie, tworzyła więc instytucje kulturalne, czego dowodem obecne istnienie Polskiego Ośrodka Społeczno-Kulturalnego z biblioteką, Instytutu Sikorskiego czy polskich archiwów w Londynie. Emigracja wspominała przeszłość nie tylko z powodu trawiącej pisarzy nostalgii, ale był to postulat polityczny, z biegiem lat coraz bardziej utopijny. Zajmowała się też wszystkim, co w kraju było przedmiotem cenzury: doświadczeniem łagrów, rozrachunkami z wielką polityką europejską i własnym dorobkiem jako świadectwem sprzeciwu.

Literatura migracyjna ma zupełnie inne dominanty. Do jej tematyki należą przede wszystkim relacje międzykulturowe, $w$ tym konfrontacja bagażu zachowań i stereotypów wyniesionych z miejsca urodzenia z nowym środowiskiem, odmiennym językowo i kulturowo oraz problemy adaptacji w nowym miejscu, próby ukształtowania nowego "ja" i dystans wobec wszelkich trwałych określeń. Migranci często wyjechali nie dlatego, że musieli, ale dlatego, że mogli, więc odpowiedź na pytanie, dlaczego tak się stało, nie jest prosta. Bo matka była dominująca, bo fajnie jest podróżować, bo pragnęli konfrontacji z dużo większym wyzwaniem niż to oferowane przez polską codzienność. Dorobek polskiej literatury emigracyjnej w XX wieku stworzyli głównie pisarze ukształtowani jeszcze w Polsce, którzy jako osobowości twórcze okrzepli przed 1939 rokiem. Oczekiwania, język i pojęcia wynieśli ze sobą. Na polską literaturę migracyjną XXI wieku w większości składa się twórczość ludzi, którzy debiutowali po wyjeździe. To doświadczenie przeniesienia się, nie w obce, lecz w nowe środowisko uczyniło z nich pisarzy.

Poza tym emigracja XX wieku to efekt zamkniętych granic i żelaznej kurtyny, która dzieliła Zachód i Wschód; dzisiejsze wyjazdy wpisują się w zupełnie inny świat kultury globalnej. Literatura migracyjna odzwierciedla sytuację współczesnego nomady; 
trzeba przypomnieć tu „podmiot nomadyczny”, termin zaproponowany przez Rosi Braidotti w książce Podmioty nomadyczne. Ucieleśnienie i różnica seksualna w feminizmie współczesnym. Feministyczna teoretyczka łączyła z tą koncepcją poważne nadzieje na uwolnienie się od trwałych, obciążonych stereotypami przeświadczeń i wyzwolenie z dogmatyzmu. Czy tak rzeczywiście się dzieje? Nie do końca, w wielu współczesnych polskich utworach studiuje się widoczne w nowych warunkach, własne uwarunkowania myślenia i zachowania wywiezione z kraju, groteskowo nieprzystawalne do nowej sytuacji, jak nieporęczny i mało użyteczny bagaż.

Przeciwieństwo między emigracją a migracją bywa jednak pozorne. W XX-wiecznej polskiej literaturze istnieje, co prawda przysłonięty przez wybijające się na pierwszy plan ujęcia polityczne, ale mimo to bardzo wyraźny kompleks zagadnień związanych z adaptacją i niskim statusem społecznym w nowym kraju. Jednym z tematów emigracyjnych powieści była próba opisu różnych matryc zachowań, polskich i brytyjskich. Sporo uwagi poświęciła temu tematowi na przykład Toporska, wznowienie w latach 2012-2013 jej powieści, po latach ich praktycznej niedostępności, pozwoliło odkryć tę pisarkę na nowo. Londyniszcze Stanisława Cata-Mackiewicza, także wznowiony, napisany z niezwykłą swadą polemiczną pamflet na polskie złudzenia, że Brytyjczycy przyjmą rolę politycznego arbitra w sprawie polskiej niepodległości, również zawiera sporą dozę bardzo interesujących obserwacji obyczajowych. Outsider - niezależnie od statusu - przez kontrast całą rzeczywistość widzi ostrzej, łatwiej mu dostrzegać i definiować miejsca, gdzie dochodzi do różnic kulturowych, bo na własnej skórze doświadczył działania odmiennych zasad, konstytuujących życie społeczne - od sposobu ubierania się po reguły rządzące życiem politycznym.

W 1952 roku Stanisław Cat-Mackiewicz w liście do Michała K. Pawlikowskiego pisał tak:

Londyn jest na pewno miastem brzydszym od Warszawy, która była oczywiście nie do porównania z cudownością Wilna, lub pięknem Krakowa, ale była ładniejsza od Poznania. Stare Miasto, linia Krakowskie Przedmieście do Łazienek, mnóstwo rzeczy było ładnych - brzydkie były ulice łączące Nowy Świat, Aleje z Marszałkowską, brzydki był plac Warecki i plac Zbawiciela, a jednak nie można tego porównać z Russell Square czy innym gównem tego rodzaju. A zresztą nie o to tu chodzi. Londyn to jest miasto, w którym nie żal umierać - jak doskonale powiedział Ryszard Kiersnowski. ${ }^{1}$

1 Cyt. za: J. Jaruzelski Stanisław Cat-Mackiewicz 1896-1966, Wilno-Londyn-Warszawa, Wyd. Instytut Kultury, Warszawa 1994, S. 273. 
Zawsze z uśmiechem przypominam sobie ten cytat, będąc w Londynie, jaskrawe rozmijanie się tego stanowiska z własnym odczuciem jest warte zastanowienia. Nie wiadomo, jaka będzie konkluzja autorów współczesnych powieści "poakcesyjnych", napisanych po 2004 roku. Obecny numer "Tekstów Drugich" zawiera opis nowego, ważnego zjawiska, rekonesans literatury w trakcie stawania się.

\section{Abstract}

\section{Anna Nasiłowska}

THE INSTITUTE OF LITERARY RESEARCH OF THE POLISH ACADEMY OF SCIENCES (WARSAW)

Emigration and Migration

This article explores the opposition between concepts of 'emigre literature' and 'migration literature'. The first has a deeply rooted tradition in nineteenth and twentiethcentury Polish literature. The Poles' migrations today are typical of global culture. And yet, some clusters of issues are shared across the board, such as the attention to cultural difference.

\section{Keywords}

emigration, migration, nomadic subject 